\title{
Religião e secularismo em debate
}

Calhoun, Craig J; Juergensmeyer, Mark; VanAntwerpen, Jonathan (orgs). Rethinking Secularism. New York, Oxford University Press, 2011, $311 \mathrm{pp}$.

Norberto Decker

Universidade Federal do Rio Grande do Sul

Rethinking Secularism (2011), editado por Craig Calhoun, Mark Juergensmeyer e Jonathan VanAntwerpen, traz importantes contribuiçôes para os estudos dedicados a analisar o modo como os termos "religiáo" e "secularismo" aparecem na esfera pública contemporânea. Através da problematização da divisão estabelecida entre "religioso" e "secular", propóe-se neste livro um debate acerca das múltiplas formas de secularismo presentes em distintos contextos sociais, políticos e culturais, com vistas a apreender os vários processos de constituição do "secular" na modernidade. Oriundos de variados campos de conhecimento, os autores da coletânea ampliam o debate proposto inicialmente pelo filósofo Charles Taylor em A Secular Age (2007) sobre as relaçóes entre secularismo e modernização.

Os dois primeiros artigos, de Charles Taylor e José Casanova, representam um referencial teórico relevante às demais análises propostas ao longo da coletânea. Taylor aponta, aqui, para o fato de a dinâmica do processo de secularizaçáo ocidental ter se caracterizado pela emancipaçáo das esferas seculares do controle eclesiástico. Produto do desencantamento e da repressão dos elementos mágicos da religiáo, a secularidade ocidental define a vida social como exclusivamente relacionada à ordem imanente (ou secular), relegando a ordem transcendente a uma invenção 
REVISTA DE ANTROPOlOGIA, SÃo PAULO, USP, $20 \mathrm{I} 5$, V. $58 \mathrm{~N}^{\circ} \mathrm{I}$.

humana, a algo supérfluo ou meramente acessório. Trata-se, então, de uma era na qual as pessoas concebem sua existência segundo um imaginário e uma razão seculares; a crença em Deus, ou em qualquer outra forma de transcendência, é vista como uma opção dentre outras possíveis. José Casanova, por sua vez, destaca a tese do "declínio" ou da "privatização" da religiáo no mundo moderno como um dos componentes centrais às teorias de secularização. Ele enfatiza que a naturalização e a universalização do secular tiveram importantes implicaçôes também nas ciências sociais, que descartaram as variedades de experiência do secular, elegendo a religiâo como objeto privilegiado de suas interpretaçóes e explicaçóes. Deste modo, o autor assevera que a tese da secularização, como um processo único e linear, permanece relativamente incontestada, de modo que a proposição de uma antropologia reflexiva do secular ainda se encontra em seus primeiros passos de desenvolvimento. A fim de ampliar a compreensão das dinâmicas do secular e do secularismo, o sociólogo sugere a produção de maiores análises voltadas às civilizaçôes não-ocidentais e um exercício crítico das categorias seculares da sociedade ocidental.

Craig Calhoun segue a indicação de Casanova ao examinar a concepção (secular) de cidadania empreendida no Ocidente, criticando a tese liberal segundo a qual a prática e o discurso religiosos devem ser excluídos da esfera pública. Repensar o secularismo, de acordo com ele, não implica necessariamente a rejeição da ideia de neutralidade do Estado quanto às religiôes, mas consiste, por exemplo, em considerar o papel das instituiçôes religiosas na conformação de uma sociedade civil global, de modo a se evitar, com isso, a perspectiva de um domínio público regido pela razão (secular), no qual a religiáo teria pouca ou nenhuma participaçáo.

Rajeev Bhargava também não rejeita a tese do secularismo político ao sugerir uma perspectiva centrada nas práticas normativas dos Estados nacionais, especialmente daqueles localizados em contextos não-ocidentais. 
REVISTA DE ANTROPOLOGIA, SÃO PAULO, USP, $20 \mathrm{I} 5$, V. $58 \mathrm{~N}^{\circ} \mathrm{I}$.

O secularismo é visto aqui não a partir de uma abordagem antirreligiosa, mas como uma forma de prevenção à homogeneização e institucionalização da dominação religiosa. Não se trata, segundo o autor, de refutar, mas sim de reabilitar o secularismo, na medida em que não se procura uma alternativa a ele, mas uma concepção alternativa de secularismo, através da qual se combata e se supere a doutrina liberal que projeta a instalação de um Estado secularizado no qual a religião é excluída de seu papel na vida pública.

Logo, a exclusão mútua entre religiáo e Estado não é uma característica que define o secularismo, tampouco se trata de uma condição necessária para o seu desenvolvimento. $\mathrm{Na}$ Índia, por exemplo, ele foi marcado por um princípio de tolerância entre as esferas religiosa e estatal, denominado pelo cientista político Alfred Stepan de twin toleration, em cujo artigo, aliás, se sustenta a tese de que o padrão de Estado separatista encontrado na França e nos Estados Unidos não é o único modelo das democracias ocidentais modernas. Segundo ele, haveria ainda dois outros padrôes não estritamente separatistas, vale dizer: o padrão established religion, dominante nas democracias da Suécia, Dinamarca e Noruega e o padrão positive-accomodation, encontrado na Holanda, Bélgica, Suíça e Alemanha. O secularismo não é também uma condição suficiente para o estabelecimento da democracia, tampouco um conceito necessário a sua análise. Deste modo, Stepan objetiva problematizar a ideia disseminada no mundo ocidental de que os muçulmanos sejam genericamente resistentes ao secularismo, lançando mão de uma análise de duas democracias majoritariamente islâmicas (Indonésia e Senegal) e de uma democracia que conta com o terceiro maior contingente islâmico do mundo (Índia). Nos três casos analisados, a predominância do princípio de tolerância entre Estado e religiáo (ou sociedade civil, de um modo geral) permite a formulação, inclusive, de um quarto modelo de secularismo, denominado pelo autor de respect all ou positive cooperation. 
REVISTA DE ANTROPOlOGIA, SÃo PAULO, USP, $20 \mathrm{I} 5$, V. $58 \mathrm{~N}^{\circ} \mathrm{I}$.

Peter Katzentein, por sua vez, traz o conceito de estados civilizacionais para pensar as múltiplas manifestaçóes de capitalismo e democracia na modernidade. Para o autor, a moderna civilização global compóe-se de uma mistura de elementos religiosos e seculares, em que o nacionalismo acaba por desempenhar o curioso papel de uma "religiáo secular". Desta forma, é possível reconhecer uma série de articulaçóes entre secularismo e religião nas políticas internacionais e um conjunto de elementos de motivação religiosa nas relaçóes (seculares) entre Estados soberanos, como nos casos da promoção global dos direitos humanos (com raízes no missionarismo protestante do século XIX) e da "guerra do terror" fomentada pelo forte (e "religioso") senso de identidade nacional americano.

A crítica à divisão rígida entre secular e religioso é reiterada no artigo de Elizabeth Shakeman Hurd, que concebe tal divisão como uma forma de estabilizar definiçóes historicamente contingentes (e geralmente hegemônicas) de política e religião. A naturalização desta dicotomia faz com que a religiáo seja relacionada a uma série de dimensôes não racionais e não universais (cultura, tradição, emoção, etc.), que devem se manter distantes do funcionamento "normal" da política. Suspender este entendimento, como defende a autora, é uma tarefa imprescindível a todos os estudos que se debruçam no tema das políticas de secularismo. Propóe-se, pois, a politicização e a historicização deste pensamento dicotômico a fim de que, com isso, se percebam as relaçôes e interdependências entre as esferas seculares e religiosas na construção de diferentes formas de ordem política e social. Tal procedimento permitiu a Hurd definir o secularismo encontrado na Turquia como um caso de twin toleration, marcado por um razoável grau de liberdade das açôes políticas frente às autoridades religiosas, de um lado, e das organizaçóes religiosas frente às instituiçôes políticas, de outro. 
REVISTA DE ANTROPOLOGIA, SÃO PAULO, USP, $20 \mathrm{I}$, V. 58 N $\mathrm{N}^{\mathrm{O}} \mathrm{I}$.

Nesta mesma linha, Mark Juergensmeyer discute os novos movimentos religiosos que identificam o Estado secular como seu potencial inimigo. $\mathrm{O}$ autor sustenta que não é a religiáo a causa da violência normalmente associada a esses movimentos, mas a maneira como a categoria "religiáo" é por eles considerada, advinda do Iluminismo europeu e das ideias secularistas de exclusão da religiáo da esfera pública. Aspecto que culminou no interessante fato de a "religião" ter se tornado cada vez menos "política" no Ocidente e o nacionalismo secular cada vez mais religioso - uma forma teleológica, quase que escatológica, do processo histórico das sociedades globais. Juergensmeyer destaca, assim, que o uso da violência por parte daqueles que rejeitam o nacionalismo secular não é apenas uma tentativa de obter maior poder dentro da vida pública, mas também uma forma de desafiar o direito e a legitimidade do Estado secular em seu monopólio da violência. Deste modo, a oposição extrema entre "religiāo" e "secular" potencializa os sujeitos que se ligam a estes movimentos religiosos a se utilizarem da mesma força que o Estado secular detém para a manutenção da ordem social.

$\mathrm{O}$ argumento de Juergesmeyer dialoga com a análise de Scott Appleby sobre a emergência de movimentos fundamentalistas globais, que, sob a orientação de uma ideologia milenarista, concebem suas açóes não apenas como uma luta mundana por território e poder político, mas como uma "guerra cósmica" e uma batalha pelo futuro da humanidade, na qual o uso da violência se apresenta como obrigatório. O autor aponta os grupos fundamentalistas religiosos como um conjunto fortemente engajado na crítica e no combate ao modelo de secularismo que marginaliza e privatiza as tradiçóes religiosas. A tese defendida ao longo de seu artigo assinala, no entanto, que a participação religiosa na vida pública e a inserção de partidos fundamentalistas na política não representam, ao contrário do que afirmam os estudos baseados na dicotomia liberal, uma ameaça para a consolidação do Estado democrático de direito. 
REVISTA DE ANTROPOlOGIA, SÃo PAULO, USP, $20 \mathrm{I} 5$, V. $58 \mathrm{~N}^{\circ} \mathrm{I}$.

Ao traçar as intersecçóes entre o religioso e o secular nas açóes humanitárias desenvolvidas por ongs ao redor do mundo, Cecelia Lynch também critica a aplicação de interpretaçôes exclusivamente "religiosas" ou "seculares" nos estudos das políticas globais de secularismo, em virtude de elas impedirem, de acordo com a autora, a percepçáo da ética religiosa e da ação no mundo secular (ou da ética secular e da ação no mundo religioso) como elementos que se entrelaçam no contexto das relaçóes internacionais contemporâneas. Seu trabalho desenvolvido na Somália, no Iraque e na Palestina junto a ativistas de ongs religiosas, que reclamam para si uma identidade secular (revelada em depoimentos como "Sim, sou muçulmano, mas sou secular") aponta para a intersecção de contextos locais com discursos globais e para o caráter instável das noçóes de secular e religioso no domínio dos atuais movimentos humanitários.

A estrutura analítica oferecida por Charles Taylor acerca do secularismo pode, então, ser estendida para além do mundo do Atlântico Norte? É com esta pergunta em mente que Richard Madsen analisa o secularismo nas sociedades asiáticas, procurando perceber as fronteiras do religioso e do secular em três contextos específicos - China, Indonésia e Taiwan. De acordo com o autor, a categoria "religiáo" presente nestes contextos diz respeito mais às noçóes de mito e rito (amplamente disseminadas na vida política, social e econômica de comunidades locais) que à noção de crença privada, adotada pela maioria das sociedades ocidentais na transição descrita por Taylor em A Secular Age (2007). Madsen sugere que a forma secular das instituiçóes políticas asiáticas seria marcada por um "espírito religioso"; e é neste ponto, diz ele, que a reflexão proposta pelo filósofo canadense se insere na discussáo sobre o lugar e o papel da religiấo na modernidade asiática, no sentido de que ela pode contribuir na investigação de como a estrutura formal dos Estados asiáticos modernos interage com este "espírito religioso", bem como na avaliação das 
REVISTA DE ANTROPOLOGIA, SÃO PAULO, USP, $20 \mathrm{I} 5$, V. 58 No I.

consequências práticas decorrentes desta relação entre a forma secular externa e o conteúdo religioso interno do aparato estatal asiático.

Peter van der Veer sugere, assim, que o secularismo seja analisado menos como um processo e mais como um projeto histórico. Em seu artigo, o antropólogo lembra que a religião (enquanto uma categoria universal) consiste em uma construção moderna relacionada ao Iluminismo e à expansão europeia dos séculos XVI e XVII. Deste modo, propóe-se examinar o secularismo na Índia e na China através da interação estabelecida entre estes países com o continente europeu, especialmente a partir da instalação do Império britânico em seus territórios. Os casos indiano e chinês serviriam, com efeito, para comprovar o fato de que o secularismo náo implica necessariamente numa postura antirreligiosa, na medida em que, nos dois contextos observados, a religiáo mostrou ter desempenhado um importante papel de mediação na organização de um projeto emancipatório e na construção das noçóes de cidadania e identidade nacional ao longo do período do nacionalismo anticolonial.

Por fim, no último artigo de Rethinking Secularism (2011), Talal Asad reflete sobre a ameaça à liberdade de expressão, particularmente nos casos em que muçulmanos acusam se tratar de blasfêmia o criticismo euro-americano dirigido publicamente ao Islá, ilustrado em episódios como o dos cartuns dinamarqueses. $\mathrm{O}$ autor analisa o lugar da blasfêmia (conceito religioso) na sociedade liberal e secular, introduzindo a ideia de sedução, central à tradição islâmica, para questionar quão clara é a distinção entre coerção e escolha racional implicada na noção de liberdade de expressão ocidental. Deste modo, Asad afirma ser importante não pressupor de antemáo a blasfêmia como uma restriçáo à liberdade humana; ao mencionar a questáo do copyright, mecanismo que oferece limites à liberdade de expressão nas sociedades liberais, o antropólogo sublinha a blasfêmia como um indicador da relevância que a liberdade de expressão 
REVISTA DE ANTROPOLOGIA, SÃO PAULO, USP, $20 \mathrm{I}$, V. $58 \mathrm{~N}^{\mathrm{O}} \mathrm{I}$.

possui em épocas e contextos distintos, revelando diferentes estruturas de poder e subjetividade. Sob esta perspectiva, Talal Asad lança, então, o intrigante desafio de se refletir acerca das razóes da sensibilidade liberal se sentir tão agredida pela violência praticada em nome de Deus, ao passo que a opressão promovida em nome da naçáo secular e da democracia náo lhe provocar uma aversão de mesma natureza.

\section{Referências bibliográficas}

TAYLOR, Charles

2007 A Secular Age. Cambridge, Mass, Harvard University Press. 